\title{
Risk assessment of the ergonomic aspects of laparoscopic theatre
}

\author{
A. Cutner • A. Stavroulis $\cdot$ N. Zolfaghari
}

Received: 25 October 2012 / Accepted: 6 December 2012 /Published online: 28 December 2012

(C) Springer-Verlag Berlin Heidelberg 2012

\begin{abstract}
An employer has a legal requirement to offer a safe working environment to its employees. The risks and hazards should be reduced as far as practicably possible, and the set-up should be as ergonomic as possible. Modern laparoscopic surgery carried out in an old-fashioned theatre without the advantages that an integrated operating room has to offer results in increased risk of injury to the staff. We have assessed the relative risks and determined reasons why modernisation is essential to the safety of the theatre team.
\end{abstract}

Keywords Laparoscopy $\cdot$ Integrated theatre $\cdot$ Ergonomics

\section{Introduction}

Operating rooms need to be fit for purpose. They are required to offer a safe environment for patients who undergo treatment and the staff who work within them. Previously, some aspects of the theatre environment were considered optional but are now the minimum acceptable standard. Examples of these include negative-pressure air conditioning [1], piped gas for anaesthetic machines [2] and laminar flow for orthopaedic joint surgery [3].

A hospital has a duty of care for the individuals responsible for surgery. The patient expectation is that the surgery will be carried out by skilled personnel in an appropriate environment.

There are certain expectations of the teams involved. Expectations of a surgeon include the following: to have the necessary skills to carry out the surgery that is planned

\footnotetext{
A. Cutner $\cdot$ A. Stavroulis $(\bowtie) \cdot N$. Zolfaghari

Institute for Women's Health, UCLH NHS Foundation Trust,

London, UK

e-mail: stavroulis@btinternet.com
}

[4], to work as a team to optimise outcome [5], to call for additional assistance where required and to forward plan this where possible. Expectations of the nursing staff are to have the correct nursing skills for the surgery, to prepare the theatre and equipment for the surgery to be carried out and to work with the surgeon to facilitate a good outcome [5].

Legally, employers must comply with relevant health and safety and employment legislation as well as the common law Duty of Care. Under the Management of Health and Safety at Work Regulations 1999, employers are responsible to complete a suitable and sufficient assessment of the risks to the health and safety that employees are exposed to whilst at work [6]. In addition, the same duty of care applies to anyone whose health and safety could be adversely affected by the employer's actions. The employer must identify risks and act upon these by instituting preventive and protective measures as far as reasonably practicable to protect the health of employees and others who may be affected.

Complying with the Duty of Care principle requires planning for the prevention of workplace-related illnesses and injuries. It is the employer's responsibilities to ensure that all reasonably practicable measures have been taken to identify workplace hazards and identify and apply preventative measures to control workplace risks against workrelated illnesses and injuries.

Thus, there is a corporate responsibility to provide a facility that optimises surgical outcome and to provide an environment that does not place the patient or staff at an unacceptable level of risk of physical injury. This paper will address the risk assessment to staff performing advanced laparoscopic surgery in an unacceptable theatre environment. We acknowledge that our article is not applicable to all areas of surgery and merely addresses the laparoscopic environment. 


\section{What is ergonomics?}

Ergonomics is "the scientific study of people at work, in terms of equipment design, workplace layout, the working environment, safety, productivity, and training". Ergonomics is based on anatomy, physiology, psychology and engineering, combined in a systems approach [7]. It is the study of designing equipment and devices that fit the human body, its movements and its cognitive abilities. In simple words, it is the science of best suiting the worker to his job.

With laparoscopic surgery, a man-machine environment has been brought into the operating room, which has created mental and physical challenges for the operating team. The science of ergonomics analyses these challenges and formulates guidelines for creating a work environment that is safe and comfortable for its operators whilst effective and efficient processes are maintained [8].

In the case of laparoscopic surgery, it is to make the setting and surroundings as favourable as reasonably practicable for the laparoscopic surgeon to do the surgery without awkward posture and with reasonable comfort [9].

\section{What is a hazard and risk rating?}

A hazard is a biological, chemical or physical agent that is reasonably likely to cause illness or injury in the absence of its control [10]. Risk is the likelihood that a specified undesired event will occur due to the realisation of a hazard by or during work activities or by the products and services created by work activities [11]. Risk in relation to occupational health and safety is defined as the likelihood that a person could be harmed by hazards in the workplace. The risk from the hazard should be determined by estimating the potential severity of harm and the likelihood that harm will occur.

Risk assessment is a tool to help an organisation or a department prevent accidents and ill health from occurring [12]. The requirement for risk assessment was first legally introduced in 1992 with the Management of Health and Safety at Work Regulations [13], even though the concept was contained within the Health and Safety at Work Act 1974 [14].

Risk rating selects or marks the values for consequences of hazards if they are not controlled (Table 1). The following risk matrix can be used to rate the risk [11]:

Risk rating $=$ Likelihood of the hazard causing harm

$$
\times \text { Severity of the consequences. }
$$

A risk rating of 16-25 (Table 2) demands immediate remedial action to remove the hazard in order to ensure patient care and safety, staff health and safety and to comply with relevant health and safety legislation [15].
Table 1 Risk rating matrix

\begin{tabular}{lll}
\hline Category & Harm (severity of the consequences) & Likelihood \\
\hline 1 & Non-injury & Almost impossible \\
2 & First aid & Unlikely \\
3 & Fewer than 3 days off work & Possible \\
4 & More than 3 days off work & Likely \\
5 & Major injury & Almost certain \\
\hline
\end{tabular}

\section{Comparison of risk between open and laparoscopic surgery}

There are many differences between open and laparoscopic surgery. Open surgery has a high degree of freedom, and surgeons work in line with their visual axis. There is a threedimensional direct vision and direct tactile feedback. There is no need for monitors, accessory equipment like gas insufflators or extra wiring. During laparoscopic surgery, there is twodimensional vision and a loss of depth perception to some extent, as well as a fulcrum effect with tremor enhancement. There are only four degrees of freedom, and the major limitation is that the view is not under the control of the surgeon.

For open surgery, the level of vision is determined by the visual acuity of the operator, the size of the incision, retractors used and the quality of overhead lighting in the operating room. The surgeon works directly on the patient with the use of traditional instruments. In contrast, to perform the surgical procedure laparoscopically, the surgeon interacts with several technological applications and equipments and requires extra wires and cables.

The increased technological complexity and sometimes poorly adapted equipment for the laparoscopic theatre environment have increased the chances of the operating team, in general, and the surgeons, in particular, of being encouraged to adopt incorrect posture and consequently suffer from fatigue and discomfort during laparoscopic surgery and thus suffer from musculoskeletal injuries.

\section{Laparoscopic surgery in a standard theatre environment}

Performing laparoscopic surgery in a conventional operating room requires additional specialised equipment otherwise

Table 2 Action required according to risk rating score

\begin{tabular}{ll}
\hline Risk rating score & Action \\
\hline $1-4$ & No further action \\
$5-9$ & Re-assess after next review \\
$10-15$ & Action within 3 months \\
$16-25$ & Immediate action \\
\hline
\end{tabular}


stored outside the theatre. Before the procedure, the theatre team must collect, prepare and connect the equipment, then take it away afterwards. These extra tasks pose a threat to efficiency and may lengthen turnover times. In addition, they increase the risk of physical injury to staff manoeuvring the equipment.

The average general operating theatre is not designed to house this equipment, leading to crowded workplaces, floors cluttered with tubing and wires, operative inefficiencies and safety problems for patients and staff [16]. The stack system is heavy to move and handle. Overall, there is an increased hazard and risk of physical harm.

The monitor is placed on top of a trolley with fixed height, and the trolley is placed wherever possible around the operating theatre. The fixed height of the trolley and its location within the operating theatre do not allow surgeons to adjust the height of the monitor in relation to their own height, and very often, surgeons are forced to adopt an awkward neck and back posture to view the operation on the monitor. Ergonomically, the best view for laparoscopy is with the monitor image at or within 25 optimal degrees below the horizontal plane of the eye. This leads to least neck strain [17, 18]. Other positions of the monitor will compromise surgical safety and result in repetitive strain injury to the surgeon. This will be exacerbated in long complex operations.

If there is one monitor and this is optimally placed for the surgeon, then the assistant who stands on the opposite side of the table is required to look over their shoulder for long periods of time. Besides neck pain, monitor positioning can be responsible for spondylosis [19].

In a non-integrated poorly designed theatre, the risk or likelihood of musculoskeletal injury during laparoscopic surgery to surgeons and their assistants and the risk of error in surgery are almost certain. The severity of the consequences or the injury to the surgeon, their assistant and to patients is quite high or major as musculoskeletal injury causes short-, medium- and long-term absenteeism amongst staff. Thus, the risk rating would be as follows:

Risk rating $(25)=$ Almost certain $(5) \times \operatorname{Major}(5)$.

This risk rating is supported in the literature. In a recent publication, $85 \%$ of laparoscopic surgeons reported suffering from work-related symptoms or injuries [20]. Much of the blame was placed on the piecemeal assembly of operating suites not designed for screen-based operations and on the co-opting of instrumentation from other specialties not intentionally designed for laparoscopic use [21, 22]. Guidelines have been introduced detailing proper positioning to minimize injuries, although implementation has been slow to non-existent [23].

Laparoscopic operations substantially increase the amount of equipment and the number of cables in the operating room. Such conditions create physical hazards for traffic in the operating theatre.

\section{Laparoscopic surgery in an integrated theatre}

The integrated theatre is a state-of-the-art system in which the laparoscopic equipment and multiple flat-screen monitors are permanently installed to be operational on demand inside the theatre. The equipment is installed in columns attached to a ceiling-mounted suspension system that facilitates versatile positioning away from the monitors. All the wiring is concealed inside the suspension system and led out through the ceiling. The laparoscopic equipment can be remotely controlled by the operating surgeon or by the circulating nurse using a touch panel at a control station. It links together, via an interface, all surgical equipment including the room and camera lights, gas insuflation and diathermy.

The Media Control provides settings that the individual surgeon can preselect, and with one button, the set-up takes place automatically. In addition, it can function as a televideo conferencing system with transmission of images and can be used for telemedicine, telementoring and remote teaching.

It is easy to be used by all theatre staff and requires minimal training. Being boom-mounted is important as this is much safer for equipment and there are no trailing cables on the floor. It enables positioning of monitors where they are required, and it is easier for staff to move around and is important for health and safety as it minimises infection risk. Efficiency during the intraoperative period is significantly improved in the integrated theatre. The theatre nurses' tasks are relieved, which may reduce mental and physical workload and improve job satisfaction and patient safety [23]. The integrated theatre is designed to reduce theatre clutter and staff workload. It increases comfort, safety and efficiency, and it enhances the ergonomics and team performance [24-26].

\section{Conclusion and discussion}

Laparoscopic surgery provides patients with less painful surgery but is more demanding for the surgeon. The benefits for patients such as smaller incisions and shorter recovery periods are well established. However, the negative effect on surgeons and the team of repeatedly performing laparoscopic operations in an inappropriate environment is only just beginning to be appreciated.

The increased technological complexity and sometimes poorly adapted equipment have led to increased complaints of surgeon fatigue and discomfort during laparoscopic 
surgery. Better ergonomic integration and understanding ergonomics can not only make the life of the surgeon more comfortable in the operating room but also reduce physical strains on the surgeon [7]. In addition, the movement of heavy equipment around a theatre complex together with increased theatre clutter increases the hazards for all staff and adds to inefficiencies.

To comply with the legal requirements and to ensure health and safety of the operating team, the ergonomic integration and suitability of the laparoscopic operating room environment are essential. Future work on the benefits of performing surgery in an ergonomically sound environment might focus on its effect on staff interactions and teamwork.

Conflict of interest Alfred Cutner received funding for Storz for lectures and education purposes.

\section{References}

1. Chow TT, Kwan A, Lin Z, Bai W (2006) Conversion of operating theatre from positive to negative pressure environment. J Hosp Infect 64:371-378

2. Love-Jones S, Magee P (2007) Medical gases, their storage and delivery. Anaesth Intensive Care Med 8(1):2-6

3. Knobben BAS, van Horn JR, van der Mei HC, Busscher HJ (2006) Evaluation of measures to decrease intra-operative bacterial contamination in orthopaedic implant surgery. J Hosp Infect 62:174-180

4. The National Institute for Health and Clinical Excellence (2009) IPG283 Sacrocolpopexy using mesh for vaginal vault: guidance. http://www.nice.org.uk/nicemedia/live/11202/42864/42864.pdf. Accessed 29 Sep 2012

5. Mousquès J, Bourgueil Y, Le Fur P, Yilmaz E (2010) Effect of a French experiment of team work between general practitioners and nurses on efficacy and cost of type 2 diabetes patients care. Health Policy 98:131-143

6. The Health and Safety Executive (HSE). Employer's responsibilities. http://www.hse.gov.uk/workers/employers.htm. Accessed 29 Sep 2012

7. Supe AN, Kulkarni GV, Supe PA (2010) Ergonomics in laparoscopic surgery. J Minim Access Surg 6(2):31-36

8. Sanders MS, McCormick EJ (1993) Human factors in engineering and design, 7th edn. McGraw-Hill, New York

9. Kilbom A (1990) Measurement and assessment of dynamic work. In: Wilson EC Jr (ed) Evaluation of human work: a practical ergonomics methodology. Taylor and Francis, London, pp 641-661
10. National Advisory Committee on Microbiological Criteria for Foods (NACMCF) (1992) Hazard analysis and critical control point system. Int J Food Microbiol 16:1-23

11. The Health and Safety Executive (HSE) (2012) www.hse.gov.uk/ quarries/education/powerpoint/topic5.ppt. Accessed 29 Sep 2012

12. The Health and Safety Executive (HSE) (2011) Five steps to risk assessment. http://www.hse.gov.uk/risk/fivesteps.htm. Accessed 29 Sep 2012

13. The National Archives (2012) The Management of Health and Safety at Work Regulations 1992. http://www.legislation.gov.uk/ uksi/1992/2051/contents/made. Accessed 29 Sep 2012

14. The Health and Safety Executive (HSE) (2012) Health and Safety at Work etc. Act 1974. http://www.hse.gov.uk/legislation/ hswa.htm. Accessed 29 Sep 2012

15. TUC (2008) Risk assessment. www.tuc.org.uk/extras/ riskassessment.pdf. Accessed 29 Sep 2012

16. Alarcon A, Berguer R (1996) A comparison of operating room crowding between open and laparoscopic operations. Surg Endosc 10:916-919

17. Menozzi M, von Buol A, Krueger H, Miege C (1994) Direction of gaze and comfort: discovering the relation for the ergonomic optimization of visual tasks. Ophthalmic Physiol Opt 14:393-399

18. Hanna GB, Shimi SM, Cuschieri A (1998) Task performance in endoscopic surgery is influenced by location of the image display. Ann Surg 227:481-484

19. Kant IJ, de Jong LC, van Rijssen-Moll M, Borm PJ (1992) A survey of static and dynamic work postures of operating room staff. Int Arch Occup Environ Health 63:423-428

20. Park A, Lee G, Seagull FJ, Meenaghan N, Dexter D (2010) Patients benefit while surgeons suffer: an impending epidemic. J Am Coll Surg 210(3):306-313

21. Berguer R, Rab GT, Abu-Ghaida H, Alarcon A, Chung J (1997) A comparison of surgeons' posture during laparoscopic and open surgical procedures. Surg Endosc 11(2):139-142

22. Nguyen NT, Ho HS, Smith WD et al (2001) An ergonomic evaluation of surgeons' axial skeletal and upper extremity movements during laparoscopic and open surgery. Am J Surg 182 (6): $720-724$

23. van Det MJ, Meijerink WJHJ, Hoff C, Tottè ER, Pierie JPEN (2009) Optimal ergonomics for laparoscopic surgery in minimally invasive surgery suites: a review and guidelines. Surg Endosc 23:1279-1285

24. Herron DM, Gagner M, Kenyon TL, Swanstrom LL (2001) The minimally invasive surgical suite enters the 21 st century: a discussion of critical design elements. Surg Endosc 15:415-422

25. Kenyon TA, Urbach DR, Speer JB, Waterman-Hukari B, Foraker GF, Hansen PD, Swanstrom LL (2001) Dedicated minimally invasive surgery suites increase operating room efficiency. Surg Endosc 15:1140-1143

26. van Det MJ, Meijerink WJHJ, Hoff C, Van Veelen MA, Pierie JPEN (2008) Ergonomic assessment of neck posture in the minimally invasive surgery suite during laparoscopic cholecystectomy. Surg Endosc 22:2421-2427 